\title{
An update on the development of mine closure and reclamation standards by the International Organization for Standardization
}

\author{
DP Murphy Golder Associates Pty Ltd, Australia \\ M Nahir Crown-Indigenous Relations and Northern Affairs, Canada \\ C Didier French National Institute for Industrial Environment and Risks, France
}

\begin{abstract}
The work program through the International Organization for Standardization (ISO), which aims to develop a series of international standards that will provide requirements and recommendations for mine closure and reclamation management, is now advanced, with two standards at committee draft level. In accordance with ISO timelines, these international standards are targeted for publication in 2020. Twelve countries are actively participating in development of these standards, with a further 11 countries observing. The two standards currently under development include one related to mine closure and reclamation terminology and one related to mine closure and reclamation planning of future or ongoing mines. A strategic plan has also been developed that outlines key themes under which further standards may be developed in the coming years. A new initiative within the work program concerning management and securing of orphan mines is currently under development.
\end{abstract}

Keywords: International Organization for Standardization, terminology, mine closure planning, standards

\section{Introduction}

The initiation, context, and drivers for the establishment of an international standards development program for mine closure and reclamation through the International Organization for Standardization (ISO) technical committee focused on mining (ISO TC 82), are presented in Steenhof (2015). Twelve countries are now actively participating in the subcommittee (ISO TC 82/SC 7) and the standards development program (Table 1).

Table 1 Countries participating and observing ISO TC 82/SC 7, mine closure and reclamation management

\begin{tabular}{ll}
\hline Participating countries (12) & Observing countries (11) \\
\hline Australia & Czech Republic \\
Cameroon & Finland \\
Canada & Mongolia \\
Chile & Poland \\
China & Romania \\
France & Russian Federation \\
Germany & Spain \\
Iran, Islamic Republic of & Sweden \\
Korea, Republic of & Tanzania, United Republic of \\
Malawi & United Kingdom \\
South Africa & Zambia \\
United States of America & \\
\hline
\end{tabular}


Since inception in 2014, ISO TC82/SC7 has held annual meetings (Seoul, Cleveland, Helsinki, Santiago, and Shanghai) to progress development of the program. The program has now established a framework for development of standards to address mine closure and reclamation across the full lifecycle of a mine. This paper provides an update on the program with specific focus on the overall strategic plan for standards development and the status of standards either under current development or being proposed.

\title{
2 Standard development framework
}

The mission, context, and framework of ISO TC 82/SC 7 are outlined within the strategic plan. Specifically, the subcommittee's mission is

\begin{abstract}
"To develop standards, guidelines and complementary documents, which when applied, will prevent and mitigate long-term mining impacts and create environmental and socio-economic value through the mine closure and reclamation management process" (International Organization for Standardization 2019).
\end{abstract}

\subsection{Scope of standard development}

It is the scope of ISO TC $82 /$ SC 7 to produce standards, guidelines, and complementary documents that address all lifecycle stages of resource development including design, development, mining, temporary suspension of operations, cessation of mining, closure, and post-closure monitoring and management. In addition to protection of the environment and creating safe and stable post-closure landforms, ISO TC 82/SC7 also seeks to address the socio-economic aspects of mine closure and reclamation including value creation and the recognition of transition to future productive land use.

In recognition of the historic mining legacy within many countries, the scope of ISO TC 82/SC 7 extends to abandoned mines, as well as to those that are currently active or being proposed for development. Accordingly, the expected audience for mine closure and reclamation standards includes both mining companies, governments, and stakeholders.

\subsection{Expectations and outcomes}

By promoting the voluntary and proactive mine adoption of mine closure and reclamation standards, ISO TC 82/SC 7 seeks to reduce potential impacts of mining activity on local communities and the environment and to promote positive re-use of land after mine closure. Additionally, ISO TC 82/SC 7 believes that appropriate standards will have the potential to promote constructive dialogue between stakeholders. Whilst the subcommittee acknowledges other industry and government lead initiatives, international standards offer a unique opportunity to develop leading practice standards through an international consensus process.

Specifically, the family of mine closure and reclamation standards will support the needs of a range of stakeholders:

- Mine operators: to demonstrate that their proposed mining procedures are aligned with global leading practices. Standards also support small and start-up mining companies with limited resources and capacity to develop their own internal standards.

- Public authorities: to align human health, environmental and socio-economic aspects of regulation with leading practices. In cases of inadequate guidance, standards can articulate and facilitate effective closure and reclamation.

- External stakeholders: to benchmark technical solutions proposed by local mining operators with leading practices for environmental protection and socio-economic benefit as outlined in standards, thereby providing a foundation for meaningful engagement. 


\subsection{Strategic plan for standard development}

Potential issues and topics of relevance to mine closure and reclamation are numerous. To avoid overloading expert volunteer involvement, ISO TC $82 /$ SC 7 has developed a strategic agenda to identify and prioritise themes. The strategic agenda is regularly reviewed and adapted, in the context of progressive development of standards and emergence of new issues and priorities. Future projects can refer to globally relevant multi-disciplinary themes or be more narrowly focused on single disciplinary areas where the need to develop a standard is demonstrated. Figure 1 presents themes currently under development, as well as new initiatives proposed for coming years. A description and rationale for each theme is summarised after the figure.

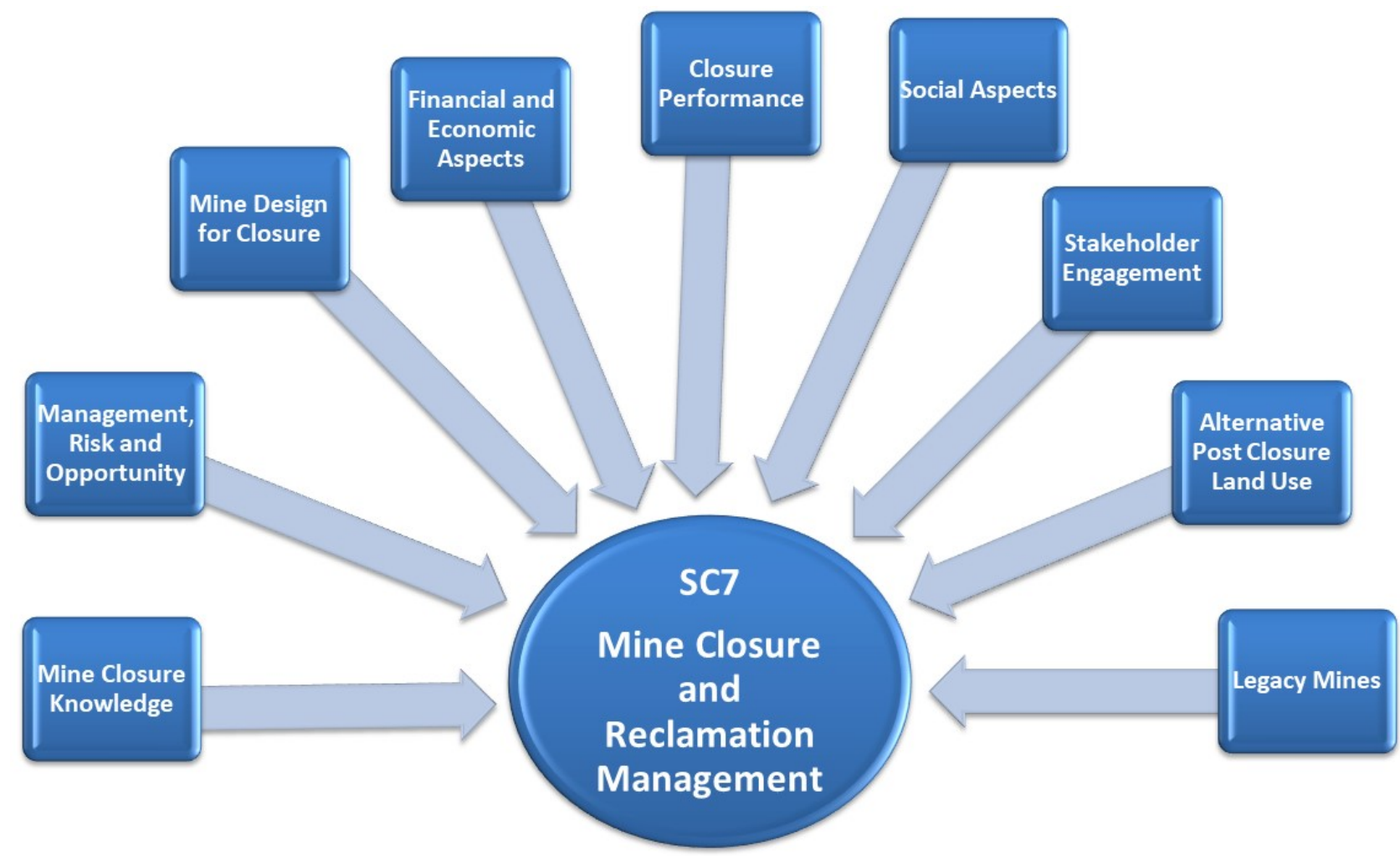

Figure 1 Key mine closure and reclamation themes within the ISO TC 82/SC 7 strategic plan

\subsubsection{Mine closure knowledge}

Mines can have very long lives during which ownership may change and important data and knowledge for closure and reclamation can be lost. Deliberate attention is required for full lifecycle knowledge management to ensure valuable baseline/early data gathered for approvals processes, and subsequent data and knowledge acquired during the life of the project are collected and remain accessible. The loss of knowledge and data is costly to replace, and its absence or inadequate management may lead to poor decisions that create significant legacy liabilities. Making mine records, knowledge, and data accessible and transparent across government and the stakeholder community (including the general public) is becoming normal practice.

\subsubsection{Management, risk, and opportunity}

Without effective standards for mine closure and reclamation, risks and opportunities to optimise closure activities may be overlooked. This can devalue the resource by creating unnecessary liability and creating conflict with external stakeholders due to misaligned expectations. Existing risk assessment standards and tools applied by industry and governments do not necessarily draw attention to the unique risks and values of mine closure and reclamation management. Hence, this theme focuses on enhancing existing systems and developing standards and guidelines that provide risk management processes to address this oversight. 


\subsubsection{Mine design for closure}

Mine facilities are best designed from the outset with closure in mind. This ensures consideration of all requirements that deliver post-closure landforms that are stable, safe, and non-polluting. Design has to consider the form and process of the mine that yields permanent changes to landscapes. An important aspect of design is consideration for all aspects of post-closure water management, as well as consideration for the localised effects of climate change. Modelling through simulation can play a key role to test and challenge design options by considering frequency and magnitude of extreme events.

\subsubsection{Financial and economic aspects}

There are statutory and regulatory requirements for reporting mine closure liability and accounting. However, guidelines and funding management mechanisms for closure and reclamation for active and abandoned mines are limited. Processes that provide leading practice mechanisms for cost accounting and financial estimations for management of the financial and economic aspects of mine closure, reclamation, and its local and regional effects are the focus of this theme.

\subsubsection{Closure performance}

Processes for proactive progressive closure and reclamation are required to demonstrate progress and performance against objectives, goals, and often completion criteria. Mechanisms to develop pre- and post-closure performance measures and leading practice indicators to demonstrate closure performance are the purpose of this theme. This can include aspects such as enhancement of biodiversity in the post-closure mine landscape, social aspects, and planning for the integration of the mine landscape into the pre-existing ecosystems or toward a chosen post-closure land use. Methods for evaluating performance include biophysical technical aspects as well as socio-economic measures.

\subsubsection{Social aspects}

This theme attends to consideration of standards and guidance across the many social aspects associated with mine closure and the transition of a mineralised area through periods of mining activity and returning to non-mining land use. Post-closure areas historically often suffer decline; hence the purpose of the theme is to develop acceptable mine closure processes that capture and manage the distinctly social aspects effectively.

\subsubsection{Stakeholder engagement}

Globally recognised as critical to effective mine closure and reclamation, this theme focuses on processes and programs that provide effective stakeholder engagement before, during, and after closure. Establishment of a realistic closure vision, assessing and engaging with communities to understand their expectations, degree and nature of engagement sought, maximising the opportunities, and the process of ongoing economic development are all aspects of this theme and future standards and/or guidelines.

\subsubsection{Alternative post-closure land use}

Formerly mined sites can be effectively developed for post-closure land uses that vary to the previous use prior to mining. This theme will provide guidelines for processes to develop options and evaluate alternative economic, environmental, or social activities that provide productive post-mining land uses. The objective is to create enhanced value during and after closure. The administrative, legal, and custodial aspect of postclosure mined land is also an aspect of this theme that warrants further development.

\subsubsection{Legacy mines}

Mining has an identified and unidentified legacy globally, and this theme looks to provide guidance to the many processes necessary to address the mining legacy and particularly those that are negatively affecting the environment and society. Primarily these sites may appear unstable, unsafe, polluting, and in many cases 
unmanaged, limiting access and use of land and water. Standards and guidance in areas of hazard and risk identification, integration of constraints, and opportunities for future land use planning, determining responsibility, policy, funding, and stakeholder engagement in decision-making are amongst aspects this theme would address.

\section{Status of mine closure and reclamation standards}

As presented by Steenhof (2015), the development of international standards through ISO follows a systematic process based on distinct stages of development involving activities at committee level (i.e. TC 82/SC 7) and working group (WG) level. This process is illustrated in Figure 2 and discussed in more detail by Steenhof (2015).

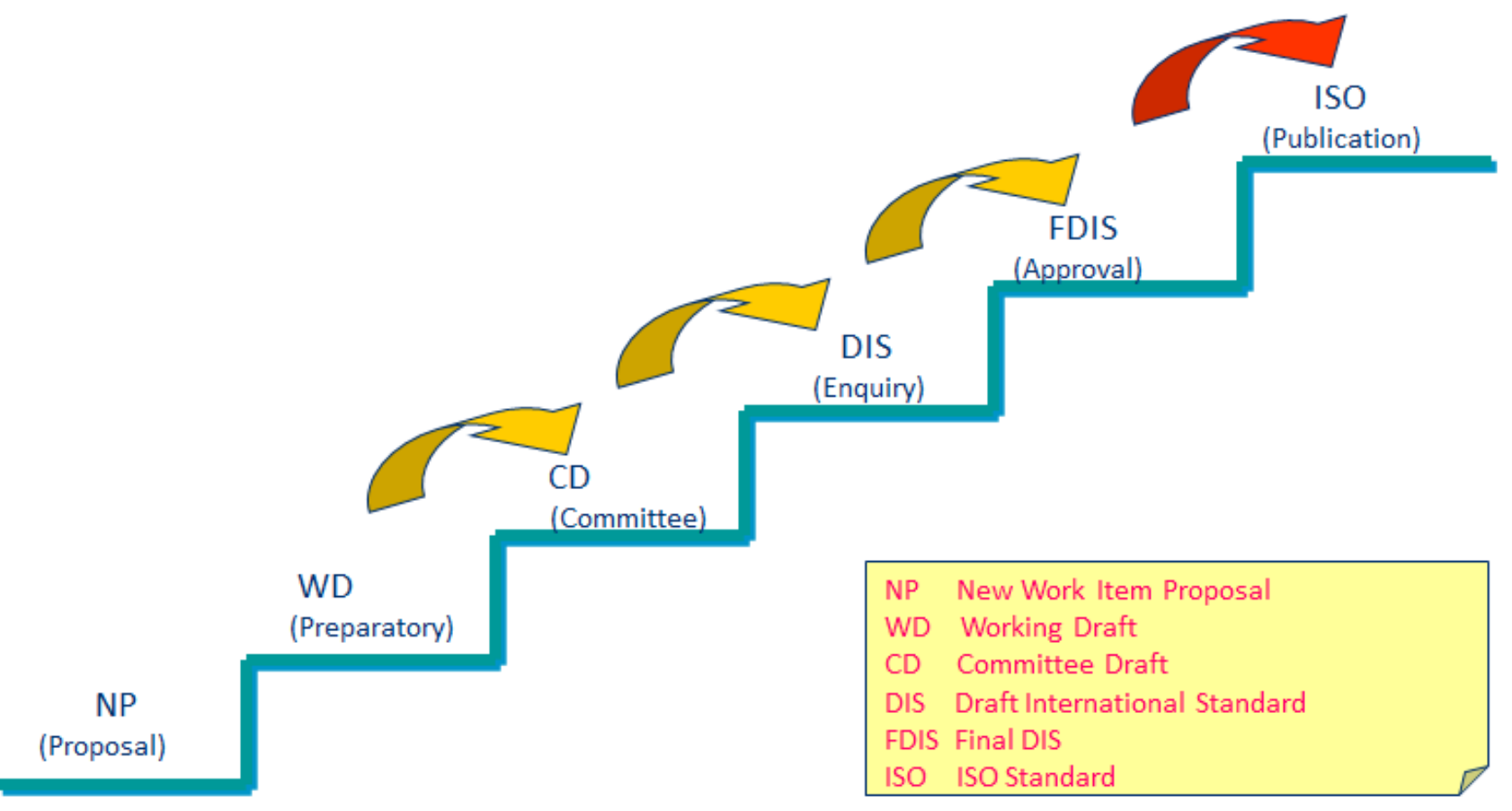

Figure 2 Stages of the International Organization for Standardization standard development process (Steenhof 2015)

Since formation, five projects have been proposed by countries participating in ISO TC 82/SC 7 . Whilst some of these projects have not progressed beyond the new work item proposal (NP) stage, it is acknowledged that the scope of the project may be aligned with specific themes within the current strategic plan and that further consideration of the purpose and scope of the project may be warranted before the project is endorsed and progressed to the preparatory working draft stage.

A summary of the current projects being considered by ISO TC 82/SC 7 is presented in Table 2, with further details of those projects that have been endorsed and progressed also presented. Preliminary work for reclamation management of abandoned mines is currently under development and a strong interest of several countries to prepare the document augurs promising perspectives for the initiative. 
Table 2 Summary and status of projects considered by ISO TC 82/SC 7

\begin{tabular}{|c|c|c|c|}
\hline Project & Purpose and scope & Status & Governance \\
\hline $\begin{array}{l}\text { Mine closure and } \\
\text { reclamation } \\
\text { terminology }\end{array}$ & $\begin{array}{l}\text { To facilitate effective communication } \\
\text { within the subject field of mine closure } \\
\text { and assist interpretation of concepts and } \\
\text { terms across all mine closure and } \\
\text { reclamation standards }\end{array}$ & $\begin{array}{l}\text { Committee draft } \\
\text { (CD) }\end{array}$ & $\begin{array}{l}\text { Working Group } 1 \\
\text { (WG1) }\end{array}$ \\
\hline $\begin{array}{l}\text { Mine closure and } \\
\text { reclamation - } \\
\text { planning }\end{array}$ & $\begin{array}{l}\text { To promote consistency and quality in } \\
\text { planning for mine closure and reclamation } \\
\text { across new and operating mines }\end{array}$ & $\begin{array}{l}\text { Committee draft } \\
\text { (CD) }\end{array}$ & $\begin{array}{l}\text { Working Group } 2 \\
\text { (WG2) }\end{array}$ \\
\hline $\begin{array}{l}\text { Abandoned mine - } \\
\text { reclamation } \\
\text { management }\end{array}$ & $\begin{array}{l}\text { To promote consistency and quality of } \\
\text { mine closure and reclamation for } \\
\text { abandoned mines }\end{array}$ & Proposal (NP) & $\begin{array}{l}\text { Taskforce } \\
\text { (informal) }\end{array}$ \\
\hline
\end{tabular}

\subsection{Terminology standard (ISO/CD 20305)}

Since inception in February 2016, and under the responsibility of ISO TC 82/SC 7/WG1, the mine closure and reclamation terminology standard, ISO/CD 20305, has progressed to the level of committee draft (CD). The deadline for publication of the standard is February 2020.

The terminology standard has been prepared to facilitate effective communication within the subject field of mine closure and reclamation, and that key terminology concepts and concept representations are agreed and used amongst participants. Specifically, the standard should be used to interpret and apply concepts and concept representations presented within mine closure and reclamation standards developed by ISO TC 82/SC 7. It indeed appeared during the WG exchanges that certain terms could have very different meanings between countries.

To prepare this standard, candidate terms were sourced from relevant mine closure and reclamation documentation and from lists provided by participants. To avoid development of quite a long list of terms, on the logic of a dictionary, candidate terms were assessed and filtered on the basis of the following criteria:

- Is the term used within, and considered critical to, ISO mine closure and reclamation standards or documentation either existing or being prepared?

- Is the term sufficiently important to avoid misunderstanding or ambiguity, such as where an alternative or conflicting definition exists or is in common use?

- Does the term express or represent a fundamental concept within mine closure and reclamation that is required to achieve a common understanding, including amongst non-expert stakeholders?

In selecting terms for inclusion within this standard, every effort has been made to exclude or avoid:

- General terms used across, and common to, subject fields other than mine closure and reclamation.

- Use of a single term for multiple concepts or multiple terms for a single concept.

- Contradictions occurring in terminological entries in other standards prepared under ISO TC 82.

Where a term was identified within the ISO terminology database, the definition was reviewed and adopted, in preference, if applicable in the mine closure and reclamation context. All terms presented within this standard have been presented from the perspective, and within the context, of the mine closure and reclamation subject field. It is acknowledged that several terminological standards are being concurrently prepared under ISO TC 82/WG 8; a separate working group under TC82 looking at general mining terminology. It is considered, however, that these standards have not progressed sufficiently to be used as normative references. 
Initial formulation of concepts from candidate terms, including revision of definitions based on concept characteristics, has been undertaken. However, such formulation of concepts is ongoing and will be reflected in further revisions of the standard. The CD terms have been classified into the following eight concepts:

1. Mine closure status: description of the current operational situation with respect to mine closure phase.

2. Mine closure phase: period during which specific mine closure activities are undertaken to achieve a specific mine closure status.

3. Mine closure activity: strategic or tactical activity applied to a mine site or mine feature to achieve post-closure land use and mine closure objectives.

4. Mine features: unique areas within mine that have a defined operational function and which requires a specific mine closure activity to achieve post-mining land use and mine closure objectives.

5. Mine materials: unique materials within a mine which present a specific risk or which require specific mine closure activities to be undertaken during mine closure.

6. Mine closure risks: specific risks and impacts associated with mine features and mine materials that require specific mine closure treatment within mine closure activities.

7. Mine closure treatments: specific treatments, measures and methods used to mitigate mine closure risks and/or achieve mine closure activities during mine closure.

8. General terms: terms that could not be currently placed in a logical concept but which are considered critical to the interpretation of mine closure and reclamation standards.

Terms and concepts within the standard are currently presented in English. Possible translation to a few other languages will be considered at the draft international standard (DIS) stage.

This standard is not intended to present a comprehensive list of all terms or concepts utilised within mine closure and reclamation. It is expected that revisions to this standard will be required as further mine closure and reclamation standards are developed under ISO TC 82/SC 7.

\subsection{Mine closure and reclamation planning standard (ISO/CD 21795)}

As for the terminology standard, the mine closure and reclamation planning standard has progressed to the level of CD.

The current $C D$ of the mine closure and reclamation standard is organised into eight clauses. It includes the fundamentals of mine closure and reclamation planning, details on each of the aspects of mine closure and reclamation planning, as well as appendices that provide guidance to support the standard.

The first section of the document addresses the fundamentals of mine closure and reclamation planning and specifically the principles required for sound planning. A summary of these draft principles is as follows:

- Closure and reclamation is a company responsibility and the associated planning shall be required by appropriate company policies and procedures, and be endorsed by company executives with enough authority to allocate the necessary financial and human resources.

- Stakeholders shall be engaged at all stages of the life-of-mine planning process and outcomes of the stakeholder engagement shall be considered in the closure and reclamation planning and implementation process.

- Measurable closure and reclamation objectives shall be established as a foundation for closure and reclamation planning.

- For new mines, mine closure and reclamation planning, including the associated post-closure land use planning, shall commence with the initial mine development planning, be included in the 
environmental assessment and permitting of the mining project, and be continually refined and updated thereafter, as necessary. For operating mines, closure and reclamation planning shall be undertaken as soon as possible in accordance with the requirements in this document.

- Closure and reclamation planning and design shall comply with or exceed the mandatory requirements within the jurisdiction in which the mine is situated.

- Closure and reclamation planning and designs shall leave the mine site in a stable and safe condition and provide for sustainable post-closure land use.

- Mine waste structures shall be planned, designed, and operated considering the requirements for the closure of these facilities.

- Risks to human health and safety and the environment, risks of failure of the closure and reclamation plan elements, and risks to achieving the post-closure and reclamation objectives shall be assessed and managed by implementing appropriate risk management plans.

- Design shall allow for enough resilience to reduce the risk of catastrophic failures to acceptable levels and to enhance the potential for the closure systems to adapt to future changed conditions.

- The company shall have policies in place that require quality assurance be performed and that it be based on a quality assurance plan that needs to be part of the mine closure and reclamation plan implementation.

- Adaptive management shall be used where necessary to facilitate the implementation of additional closure and reclamation measures.

- The company shall develop a financial plan which provides for the financial resources to implement the closure and reclamation plan.

- The post-closure phase shall provide for ongoing environmental protection and land use and shall include site management. Secure long-term funding shall be available to support these activities.

Subsequent to the above principles, the standard presents key elements of the mine closure and reclamation planning process aimed at developing cost-effective closure and reclamation plans and designs that can be implemented and which will find acceptance by regulatory agencies and affected local communities and Indigenous populations.

It is intended that the outcome of this planning process be documented to provide a record, provide for continuity of implementation, and be endorsed by the communities, regulators and company's senior management.

The key elements of the mine closure and reclamation planning process for which guidance is currently presented within the standard are summarised as follows:

- Establishment of drivers including regulatory and company requirements to determine how closure and reclamation will be conducted.

- Investigation of technical requirements including land use planning and site characterisation.

- Assessment of alternatives for mitigation of physical and chemical risks, remediation of residual contamination, and design of final landforms.

- Scheduling, cost estimation, and planning for progressive and final execution.

- Identification and management of socio-economic requirements including risks and opportunities.

- Development of a financial plan and provision of sufficient funding to ensure successful completion of closure and reclamation activities.

- Planning for temporary cessation of mining operations. 
- Planning for long-term, post-closure management and monitoring including adaptive management, care and maintenance and site relinquishment.

- Documentation, revision, and management of closure and reclamation plans and associated data.

The remaining sections of the standard in CD version provide guidance in support of the principles and key process elements for mine features and facilities including:

- Tailings management facilities.

- Mine rock management facilities.

- Heap leach facilities.

- Open pits.

- Underground workings.

- Mine infrastructure.

\section{$4 \quad$ Next steps and schedule}

ISO standards are developed to a rigorous schedule. Respectively, the mine closure and reclamation terminology and planning standards must be issued as DIS by August 2019 and March 2020. Prior to this, comments and feedback from participating countries on the CDs will have been compiled and addressed to prepare each DIS. Review of the DIS by ISO member bodies will approximately require five months before moving through to final draft international standards and finally as an ISO international standards. Each standard will be required to meet the voting outcomes before moving to the next stage. If insufficient support is received at any stage, additional time will be required to resolve outstanding concerns before a further ballot is undertaken to progress the standard. Extensions to time may be granted, however, a maximum time limit does apply. Standards that do not reach publication by the required time may be withdrawn and the timeline reset with a new work item proposal (i.e. NP) required. With all going well, the mine closure and reclamation terminology and planning standards will be published prior to February 2020 and September 2020, respectively.

The NP for abandoned mine management is expected to be submitted for consideration at the next ISO TC82/SC 7 plenary session schedule for late 2019 in Stockholm. Ongoing development of further NP in accordance with the ISO TC82/SC 7 strategic plan will continue as required indefinitely.

\section{$5 \quad$ Involvement in standard development}

Over 163 nations are members of ISO. National participation in development of standards is facilitated through national standards organisations (e.g. Standards Australia). Such organisations will generally establish specific committees aligned to ISO technical committees to support the development and review of standards. Participating nations may nominate individuals from these committees to contribute to the preparation of standards through WGs. Membership of national 'mirror' committees is subject to the specific rules of respective national standards organisations. Individuals or organisations with an interest in participating in the future development of ISO mine closure and reclamation standards are encouraged to contact the relevant national standards organisation.

\section{Conclusion}

Under the ISO technical committee framework, a subcommittee for the establishment of mine closure and reclamation standards has now been established (i.e. ISO TC 82/SC 7). A strategic plan has been developed to guide the preparation of these standards for mine closure and reclamation terminology and planning is now in CD stage and expected to enter DIS stage in late 2019. With the required level of support from ISO member bodies, publication of the mine closure and reclamation terminology and planning standards is 
expected sometime in 2020. New work item proposals for additional standards and guidance documents are now also in preparation, or under consideration, in accordance with the strategic plan.

\section{Acknowledgement}

Members of National Mirror Committees and ISO committees and WGs represent not-for-profit, industrybased, professional, research or government organisations. Their time is voluntary and generally supported by their employers as necessary. The time and input of these committee members, as well as that of the staff of the supporting national standards organisations, and of ISO itself, is essential to this work and is greatly appreciated.

The support and contribution of the International Council for Mining and Metals and its members is also appreciated for value feedback on working drafts of the mine closure and reclamation planning standard.

\section{Reference}

International Organization for Standardization 2019, Strategic Plan, Internal Technical Committee 82, Subcommittee 7 document, unpublished.

Steenhof, P 2015, 'Development of international standards for mine reclamation management', in AB Fourie, M Tibbett, L Sawatsky \& D van Zyl (eds), Proceedings of the 10th International Conference on Mine Closure, Australian Centre for Geomechanics, Perth, pp. 157-168. 